\title{
Usefulness of composite restoration in direct esthetic closure of midline gap
}

\begin{abstract}
Introduction. Midline gap (diastema) is a space between two teeth, commonly between two incisors. The treatment can be provided by orthodontic, conservative (restorative) or prosthetic methods.

Aim. The aim of the study was an assessment of using direct composite restoration in aesthetic closing of diastema.

Material and methods. The space correction between teeth was performed among female and male adult patients with diastema of 3 to $6 \mathrm{~mm}$. The microhybrid resin composite was used for the composite build-ups with a help of celluloid or silicon matrix due to its good handling properties and shade matching, and polishability properties.

Results. Depending on the size of diastema, the partial or total closing was done to achieve the cosmetic effect. The obtained clinical results were highly assessed both by dentists and patients. It was possible to obtain optimal aesthetic results with resin composite restorations only.

Conclusions. The simple closure of diastema with direct composite reconstructions can result in successful outcome and patient's satisfaction.
\end{abstract}

Keywords: midline gap, diastema, diastema closure, composite restoration.

DOI: $10.2478 /$ pjph-2014-0020

\section{INTRODUCTION}

Maxillary midline (central) diastema is a dental malocclusion characterized by a space between maxillary central incisors. Diastema is a physiological phase developing in children after central incisors eruption called "ugly duckling" stage [1]. In permanent dentition after canines eruption, the diastema should be closed. According to Andrews' keys to normal occlusion, contact points between teeth should be kept in permanent dentition [2].

The following environmental reasons for the maxillary midline diastema are mentioned: tooth size or jaw size discrepancies [3,4], aberrant labial frenum attachments $[4,5]$, parafuncial habits, tooth loss, periodontal disease [4], deep bites [3], supernumerary teeth [6]. Some authors proved familial correlations and heritability of maxillary midline diastema $[5,7]$. Guess et al. have suggested there may be genetic susceptibility to the development of midline diastema [7]. There have also recently been reported self-inflicted pathological cases of diastema caused by tongue piercing [8].

In some regions of the world, diastema is regarded as a mark of natural beauty especially for women [9]. Small maxillary central diastema between the maxillary central incisors is not rated as unattractive. Dentists and laypeople do not rate unattractive until the distance between the central incisors is $2 \mathrm{~mm}$ [10]. Central diastema wider than $2 \mathrm{~mm}$ is an aesthetic problem and has an impact for daily living [11]. One of the widest announced in literature was $14.5 \mathrm{~mm}$ [6].

A diastema treatment can be different depending on indications and size of the gap between central incisors. Orthodontic treatment should be done in cases with a large diastema, where parallel movement of teeth is required. Also when other malocclusions coincidence with diastema orthodontic treatment is indicated $[4,6]$. In case where supernumerary teeth were observed, surgical procedures with extraction of those teeth and bone graft in place after extraction were needed before starting orthodontic diastema treatment [6]. A problem after orthodontic treatment of median diastema is relapse [12-14], which can refer to even $50 \%$ of patients [12]. The most predictive factors of diastema relapse include the initial large size of the diastema, family occurrence, additional spaces between maxillary anterior teeth [12] and proclination of maxillary incisors [14], so that permanent retention is required.

A small diastema without coincidence of maloclusions can be closed by resin composite restorations. This method is fast, noninvasive and low cost [15-17]. Also prosthetic device as crowns, veneers or sectional porcelain veneers [18] could be made for diastema closure.

\footnotetext{
${ }^{1}$ Department of Conservative Dentistry and Endodontics, Medical University of Lublin, Poland

${ }^{2}$ Department of Jaw Orthopedics, Medical University of Lublin, Poland
} 


\section{AIM}

The aim of the study was to assess the usefulness of the composite material in aesthetic diastema closure.

\section{MATERIAL AND METHODS}

The aesthetic diastema correction was done among male and female adult patients of the Department of Conservative Dentistry and Endodontics in Lublin, Poland. After clinical examination and orthodontic consultation, the diastema between frontal teeth - mesial incisors of every patient was measured with a ruler. The obtained measurements ranged from 3 to $6 \mathrm{~mm}$. Depending on the size of diastema, the partial or total closing was done to achieve the cosmetic effect. Tooth tissues were prepared with a special diamond borer, and after etching and bonding procedure, the aesthetic composite restoration with a help of celluloid or silicon matrix was made. The microhybrid resin composite was used for the composite build-ups due to its good handling properties, shade matching, and polishability properties. The concept of natural incremental technique was performed to improve the aesthetics of the fillings and the integration of the composite with tooth tissues $[15,19]$. According to this technique, the dentine opaque shades and enamel shades were used for restoring missing tissues. After closing the space between incisors, finishing and polishing of the restorations took place with finishing/polishing discs in the sequence recommended by manufacturer. The photographical documentation was made before and after procedure of every patient.

\section{RESULTS AND DISSCUSSION}

The composite material was smoothly adapted to the tooth hard tissues and after the final polishing and rehydration period the effect was very good. The obtained clinical results were highly assessed by dentists and patients. The patients were satisfied with their appearance after closing diastema. As shown on pictures, it was possible to obtain optimal aesthetic results with composite restorations only. Chosen clinical situations of performed restorations are presented on Figures 1-4.

The midline diastema occurs in approximately $98 \%$ of 6 year-old children, $49 \%$ of 11 year-olds, $7 \%$ of $12-18$ yearolds and $6 \%$ of adults [6]. The appearance of anterior teeth with diastema may form a picture of patient with unacceptable aesthetic presentation for him/her. In clinical cases where conservative, aesthetic correction of anterior teeth is indicated, direct composite restorations may be preferable. However, "black triangles" is the problem for restorative methods. Black triangles are spaces that appear between teeth, when the papilla does not follow the contact point of tooth and exposes black background of the oral cavity. The appropriate location of the contact point is fundamental for aesthetics [17]. According to Tarnow [20], when the distance between the contact points is $5 \mathrm{~mm}$ or less, there is $100 \%$ presence of interdental papilla, and that ensures a good relation between teeth and gums. In our case, the use of direct reconstruction, such as recontouring of tooth shape and closing diastema provided the symmetrical and harmonious
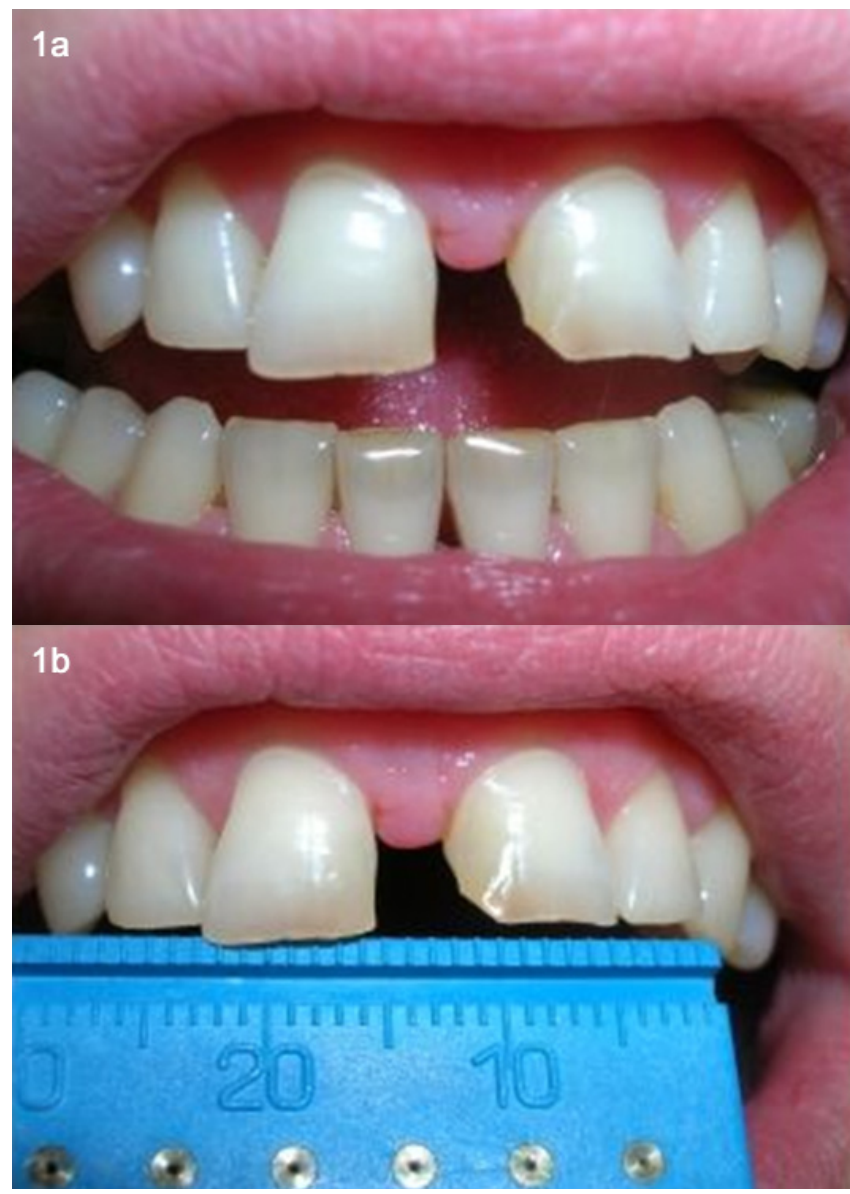

FIGURE 1a, 1b. $5 \mathrm{~mm}$ diastema between upper incisors before restoration.

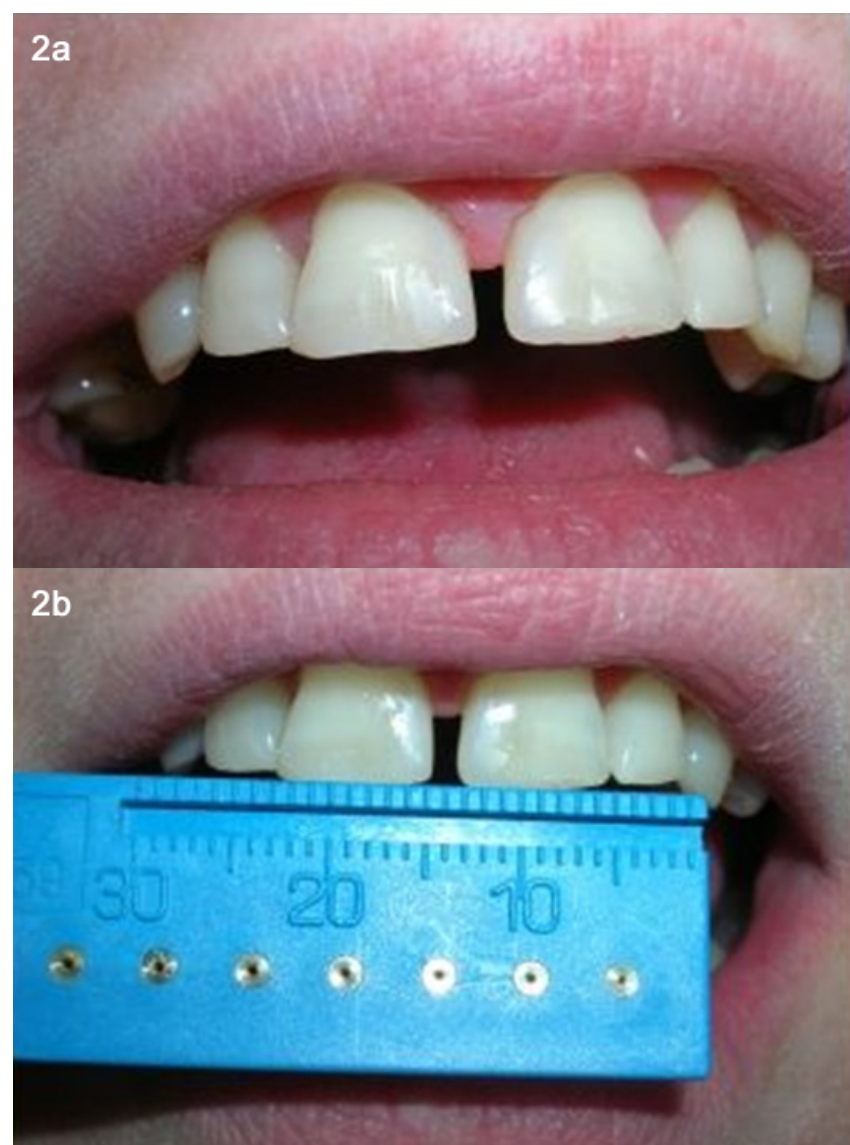

FIGURE 2a, 2b. After treatment - 2 mm diastema. 


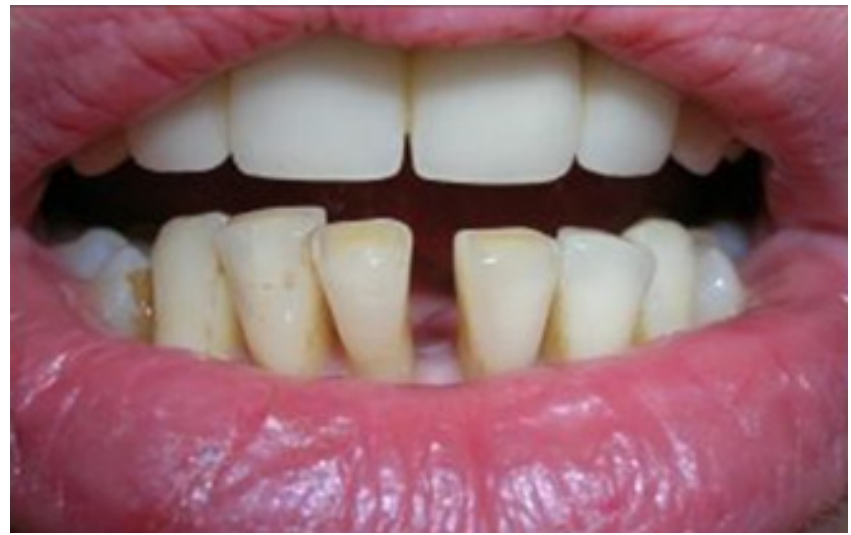

FIGURE 3a. Diastema between mandibular central incisors.

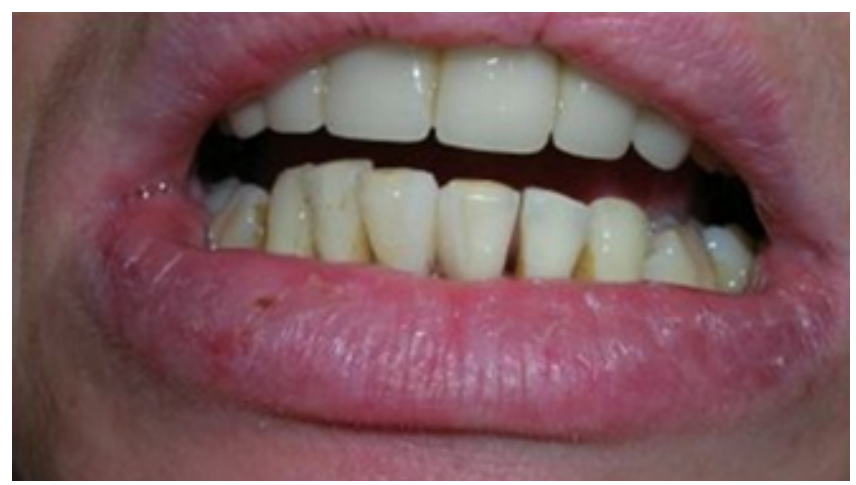

FIGURE 3b. After total closing of diastema.

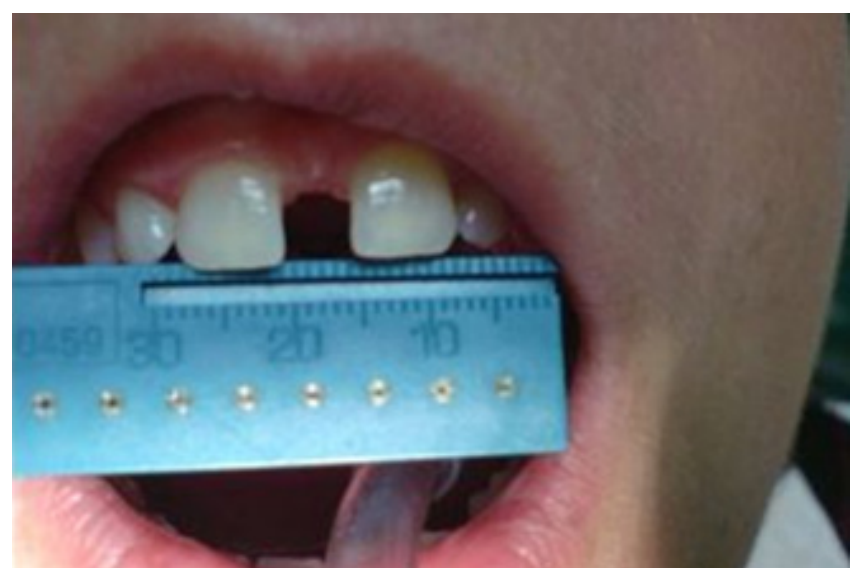

FIGURE 4a. 6 mm maxillary central diastema.

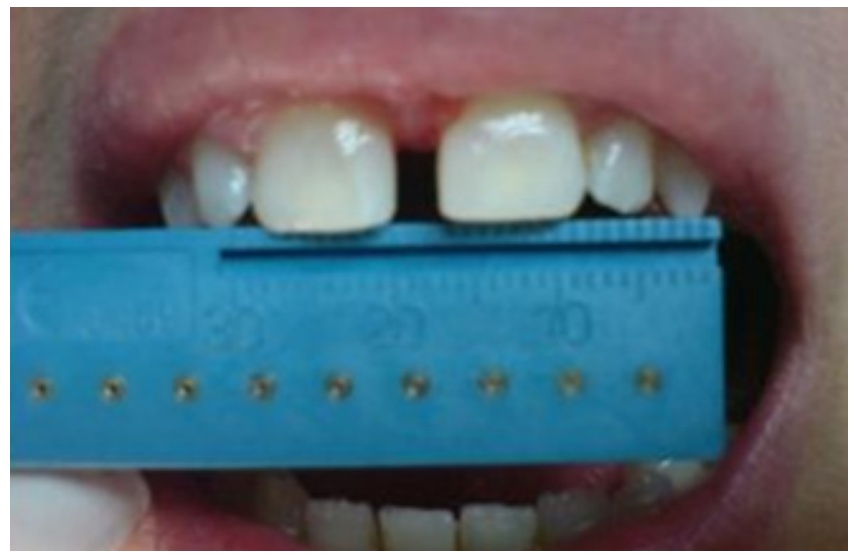

FIGURE 4b. After partial closing - $3 \mathrm{~mm}$ diastema left. arrangement of the teeth. Even in some cases when it was not totally closed, the patient was satisfied with the result. However, in difficult cases for better aesthetic results, where the correction or management cannot be done by the composite restorative technique only, an interdisciplinary approach is often required $[6,21]$.

There are many advantages of direct composite reconstruction and closing diastema at one visit, for both dentists and patients, especially where maximal conservation of healthy tooth structure is necessary. According to minimally invasive dentistry rules, this technique fits them properly. The color, shape and tooth position can be corrected at once. The procedure is reversible and low cost to the patient comparing with ceramic/porcelain restorations. It can be easy removed when a patient does not accept it. When a small correction is necessary, it can be done immediately and with small cost effect. And there is no need of the dental technician's help [15-18,21]. Furthermore, it is an alternative method for the invasive prosthetic reconstruction with a veneer or crown, and this can be confirmed by our cases.

\section{CONCLUSION}

The simple closure of diastema with direct composite build-ups can result in successful outcome and patient's satisfaction. It seems to be a practical and conservative method of treatment.

\section{REFERENCES:}

1. Broadbent BH. The face of the normal child. Angle Orthod. 1937;7(4):183-208.

2. Andrews LF. The six keys to normal occlusion. Am J Orthod. 1972;62(3):296-309.

3. Oesterle LJ, Shellhart WC. Maxillary midline diastemas: a look at the causes. J Am Dent Assoc. 1999;130(1):85-94.

4. Huang WJ, Creath CJ. The midline diastema: a review of its etiology and treatment. Pediatr Dent. 1995;17(3):171-9.

5. Delli K, Livas C, Sculean A, et al. Facts and myths regarding the maxillary midline frenum and its treatment: a systematic review of the literature. Quintessence Int. 2013;44(2):177-87.

6. Campbell A, Kindelan J. Maxillary midline diastema: a case report involving a combined orthodontic/maxillofacial approach J Orthod. 2006;33(1):22-7.

7. Gass JR, Valiathan M, Tiwari HK, et al. Familial correlations and heritability of maxillary midline diastema. Am J Orthod Dentofacial Orthop. 2003;123(1):35-9.

8. Rahilly G, Crocker C. Pathological migration: an unusual cause of midline diastema. Dent Update. 2003;30(10):547-9.

9. Onyeaso CO. Prevalence of malocclusion among adolescents in Ibadan, Nigeria. Am J Orthod Dentofacial Orthop. 2004;126(5):604-7.

10. Kokich VO, Kokich VG, Kiyak HA. Perceptions of dental professionals and laypersons to altered dental esthetics: asymmetric and symmetric situations. Am J Orthod Dentofacial Orthop. 2006;130(2):141-51.

11. Marques LS, Filogonio CA, Filogonio CB, et al. Aesthetic impact of malocclusion in the daily living of Brazilian adolescents. J Orthod. 2009;36(3):152-9.

12. Shashua D, Artun J. Relapse after orthodontic correction of maxillary median diastema: a follow-up evaluation of consecutive cases. Angle Orthod. 1999;69(3):257-63.

13. Mattos CT, da Silva DL, Ruellas AC. Relapse of a maxillary median diastema: closure and permanent retention. Am J Orthod Dentofacial Orthop. 2012;141(1):e23-e27.

14. Sullivan TC, Turpin DL, Artun J. A postretention study of patients presenting with a maxillary median diastema. Angle Orthod. 1996;66(2):131-8. 
15. Dietschi D. Optimizing smile composition and esthetics resin composites and other conservative esthetic procedures. Eur J Esthet Dent. 2008;3(1):14-29.

16. Lenhard M. Closing diastemas with resin composite restorations. Eur J Esthet Dent. 2008;3(3):258-68.

17. De Araujo EM Jr, Fortkamp S, Baratieri LN. Closure of diastema and gingival reconturing using direct adhesive restorations: a case report. J Esthet Restor Dent. 2009;21(4):229-40.

18. Signore A, Kaitsas V, Tonoli A, et al. Sectional porcelain veneers for a maxillary midline diastema closure: a case report. Quintessence Int. 2013;44(3):201-6.

19. Sapuła M, Wolańska E, Jarmolińska K. Evaluation of operating properties of Filtek Z550 composite material according to Ryge - preliminary report. J Stoma. 2013;66(3):331-40.

20. Tarnow DP, Magner AW, Fletcher P. The effect of the distance from contact point of the crest of bone on the presence or absence of interproximal dental papilla. J Periodontol 1992;63(12):995-6.

21. Hwang SK, Ha JH, Jin MU, et al. Diastema closure using direct bonding restorations combined with orthodontic treatment: a case report. Restor Dent Endod. 2012;37(3):165-69.

\section{Corresponding author}

Dr hab. n. med. Renata Chałas

Karmelicka 7 st., 20-081 Lublin, Poland

tel. (81) 528-79-20

E-mail: renata.chalas@gmail.com 